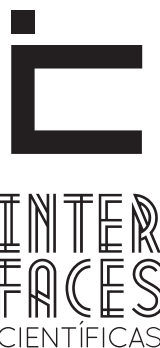

EDUCAÇÃO

ISSN IMPRESSO 2316-333X

ISSN ELETRÔNICO 2316-3828

\title{
A DOCÊNCIA SOB SUSPEITA: AS REPRESENTAÇÕES DE GÊNERO NO CAMPO DA EDUCAÇÃO
}

Alfrancio Ferreira Dias ${ }^{1}$

\section{RESUMO}

Este artigo aborda as representações de gênero no campo da educação, destacando as experiências de socialização do trabalho docente, a partir das trajetórias escolares, familiares e profissionais, o sentido e significado do trabalho na perspectiva dos/as docentes e o trabalho como uma categoria central e imaterial na vida dos/as docentes. A metodologia utilizada neste trabalho apoia-se em análises de fontes bibliográficas e em resultados de pesquisas de campo com diferentes dimensões metodológicas. Infere-se que os/as docentes vivenciam as mudanças
Maria Helena Santana $\mathrm{Cruz}^{2}$

das relações no interior do trabalho e na família, atribuindo sentidos ao trabalho que realizam a partir de suas identificações como professores/as e homens/mulheres, construídas no decorrer de suas trajetórias.

\section{PALAVRAS-CHAVE}

Trabalho Docente. Relações de Gênero. Sentido do Trabalho. 


\section{ABSTRACT}

This article addresses the representations of gender in education, highlighting the socialization experiences of teaching from school trajectories, families and professionals, the sense and meaning of the work from the perspective of the teachers and the work as a central and immaterial category in the life of the teachers. The methodology used for this study is based on analysis of bibliographical sources and in results of field research with different methodological dimensions. It is inferred that the teachers experience the changing of the relations within the work and family, assigning senses to their work from their identification as teachers and men/women, constructed in the course of their trajectories.

\section{KEYWORDS}

Teacher work. Gender Relations. Sense of Labour.

\section{RESUMEN}

Este artículo aborda sobre las representaciones de género en la educación, destacando las experiencias de socialización de la enseñanza, partiendo de las trayectorias escolares, familiares, profesionales, fijándose en la importancia y el significado de ésta obra desde la perspectiva de los profesores, destacando éste trabajo como una categoría central e inmaterial en la vida de los / docentes. La metodología empleada en este trabajo, se basa en el análisis de las fuentes y los resultados de las pruebas con diferentes dimensiones metodológicas. Frisase aun, que los docentes enfrentan los cambios dentro de su trabajo y familia, pues ellos suelen desarrollar su trabajo, bajo una identidad como maestros / hombres / mujeres, construidas a lo largo de sus experiencias y trayectorias. .

\section{PALABRAS CLAVE}

El trabajo del Profesor. Relaciones de Género. Sentido del Trabajo.

\section{INTRODUÇÃO}

O tema desta investigação, acerca das relações de gênero no trabalho docente no Colégio Estadual Atheneu Sergipense, surgiu ao longo trajetória do pesquisador como profissional na docência (ensino e pesquisa) na Universidade Estadual do Sudoeste da Bahia, e se acentuou por meio da participação em atividades acadêmicas, no grupo de pesquisa "Educação, Formação, Processo de Trabalho e Relações de Gênero", e no "Núcleo de Estudos e Pesquisas Interdisciplinares sobre a Mulher e Relações de Gênero" - NEPI$M G$, vinculado à Universidade Federal de Sergipe. As reflexões e as atividades desenvolvidas contribuíram para a emergência do interesse inicial desta pesquisa, na medida em que a docência é pensada aqui "como uma forma particular de trabalho sobre o humano, ou seja, uma atividade em que o trabalhador se dedica ao seu 'objeto' de trabalho, que é justamente outro ser humano, no modo fundamental da interação humana" (TARDIF; LESSARD, 2009, p. 8). Nesse sentido, o trabalho docente é entendido como um espaço de interações sociais que repercutem sobre seus conhecimentos, identificações e experiências profissionais.

Nos dias atuais, as pesquisas sobre mudanças no mercado de trabalho formam um campo multidisciplinar. As questões do trabalho são analisadas em instâncias diferentes das relações interpessoais. Tais categorias de análise constituem o fundamento do 
caminho deste artigorelativo a relações de gênero no trabalho docente. Com o principal desafio de refletir sobre alguns resultados da pesquisa de doutoramento em Sociologia intitulada "As representações de gênero no trabalho docente: um estudo de caso no Colégio Estadual Atheneu Sergipense".

A opção metodológica recaiu na abordagem qualitativa, por se considerar a necessidade de um conjunto de técnicas interpretativas para expressar o sentido dos fenômenos sociais e a compreensão dos significados das ações e relações humanas. Nesta perspectiva, o estudo de caso mostrou-se relevante para o conhecimento das situações concretas de trabalho dos/as docentes, para que, a partir da trama das relações sociais observadas, possam ser apontados elementos capazes de informar análises que contribuíssem para a melhor compreen-

\section{AS REPRESENTACÇÕES SOBRE O COTIDIANO DO TRABALHO}

0 trabalho docente como um espaço de sociabilidade é pensado aqui, considerando três aspectos: como fonte de realização dos agentes, como elemento de apropriação da autonomia e como elemento central na vida dos trabalhadores (ARAÚJO \& SCALON, 2005). Acredita-se que esses aspectos são fundamentais para a análise das representações dos/ as docentes, na medida em que o primeiro remete às perspectivas de realizações individuais como sua posição, visibilidade e conquistas; o segundo diz respeito à autonomia dos agentescujas necessidades econômicas podem ampliar a relação tempo/espaço dos trabalhadores, passando mais para uma relação de ganho do que de valor. 0 último aspecto influencia a construção das identificações dos/as agentes no campo do trabalho. são das transformações nas relações sociais de gênero. Para a coleta de dados foram aplicados 22 questionários (13 mulheres e 9 homens) e realizadas 16 entrevistas semiestruturadas (8 mulheres e 8 homens) no ano decorrer de 2011. A abordagem teórico-metodológica utilizada para a questão de gênero, como todas as questões de sentido, foi desenvolvida de forma sistematizada, particularizada, especificada e localizada historicamente, objetivando captar os nexos que estruturam as representações dos sujeitos participantes da pesquisa.

Neste sentido, pretende-se mostrar as transformações vivenciadas nos últimos anos do trabalho docente no Ensino Médio do Colégio Estadual Atheneu Sergipense, avaliando as mudanças nas relações sociais de gênero, bem como a ampliação da cidadania e dos direitos dos/as docentes.
Nessa perspectiva, entende-se que, para compreender as representações masculinas e femininas no cotidiano das relações de trabalho, é preciso entender o gênero como uma perspectiva de análise útil, concebido com a ideia de que é preciso ampliar o conceito de trabalho reprodutivo/assalariado para incluir, também, o trabalho reprodutivo/não assalariado, pois esses aspectos estão presentes em efervescência nas representações dos/as docentes acerca das relações cotidianas de trabalho e de família.

As representações de gênero relativas ao trabalho docente anunciam a existência de estereótipos ligados à masculinidade e à feminilidade reconhecidos, prioritariamente, pelas mulheres consideradas as suas vivências no campo do trabalho, ao mesmo tem- 
po em que se percebe nas narrativas que estas estão representando os processos de relações do "eu" com os "outros" (homens/mulheres, mulheres/mulheres e homens/homens), ou seja, da alteridade. Nessa linha de reflexão, Cruz (2012, p. 9) argumenta que a "questão da sociabilidade e da identidade" no campo da educação; segundo as argumentações da autora, as representações, a sociabilidade e as identificações dos/as docentes dependem da "trajetória de vida do indivíduo e da configuração social de cada momento de sua vida, permitindo a existência de socializações posteriores àquela primeira socialização familiar”.

Assim, compreende-se que homens e mulheres participam de processos de socializações no decorrer de suas trajetórias familiar, escolar e profissional, de forma ativa/passiva, num processo de influenciar/ser influenciado um ao outro, reproduzindo um discurso social e cultural. Em outras palavras, a diversidade de homens e mulheres nas relações de trabalho pode interferir nessa reprodução, pois as identidades de gênero não são rígidas, mas sim plurais. A cultura é um conjunto de significados/significantes que, por meio das tradições, se desvia para uma nova forma de situar-se, produzir-se, no sentido mais amplo, num processo de metamorfose em que novos conceitos, compreensões e caminhos permitem o surgimento de novos sujeitos. Esse processo de metamorfose admite refletir quanto ao caminho que homens e mulheres percorrem,

[...] perante nossas tradições e, se esse caminho está sendo codificado a partir das intervenções do cotidiano, pois o "fazer" pressupõem reconstruir-se a partir de debates advindos da contestação da tradição e a nova forma de pensar contemporaneamente a cultura (DIAS, 2011, p. 154).

O gênero é pensado como uma construção social e cultural (SCOTT, 1995). A adoção do conceito de gênero no âmbito dos estudos de mulheres e feministas tornou o gênero como campo científico. O conceito de gênero é compreendido como um divisor de águas para outra fase distinta da primeira onda do femi- nismo, e anunciador, de certa forma, da valorização significativa do diferencialismo, da afirmação política das diferenças, dos processos identitários e de igualdades; ou seja, o conceito chama a atenção para a diversidade ou as diferenças dentro da diferença. No campo das interações sociais, masculinidades e feminilidades são ressignificadas num processo complexo, no qual as relações de trabalho influenciam o significado atribuído às diferenças entre os sexos. Quanto ao trabalho dos/as docentes, buscou-se compreender as transformações vivenciadas no cotidiano das relações de trabalho, situando os avanços nas relações sociais de gênero para a ampliação da cidadania de homens e mulheres.

As representações sociais relativas a homens e mulheres docentes são pensadas em conformidade com o trabalho que realizam, num espaço de relações dinâmicas e ambíguas, que descrevem as narrativas, as imagens de gênero, os papéis de homens e mulheres, das masculinidades e feminilidades que configuram as práticas de socialização no trabalho. Parte-se da premissa de que a socialização é significante para a construção das identificações dos agentes, visto que, nesse processo, as percepções, os discursos, as assimetrias são questionadas na interação. Especificamente no campo da educação, os espaços de socialização precisam ser ampliados e ressignificados como argumentam alguns dos entrevistados:

\footnotetext{
Precisam ser melhoradas, [...] precisa ser dada mais oportunidade de diálogo, tendo em vista que cada professor vem para a escola realiza seu trabalho, volta para casa sem dar espaço para o outro, para trocar experiências, vivências pedagógicas, porque isso eu vejo muito pouco atualmente, ficando no campo das particularidades, da competição entre os colegas (Professora, solteira, 47 anos, dois filhos, Doutora, 15 anos na Rede Estadual).
}

Acredito ser necessário ampliar mais os nossos vínculos porque nós nos tornamos muito individualizados, cada um com suas tarefas, que no decorrer do dia apenas no intervalo para cafezinho é que conversamos um pouco, mais muito rapidamente. Ainda falta muito esse espaço de socialização, de diálogos para que eu 
possa realmente conhecer o outro, suas especificidades, seus valores e habilidades, pois a interação pode nos transformar sempre, eu acredito nisso e sonho com isso (Professor, casado, 42 anos, três filhos, Especialista, 13 anos na Rede Estadual).

As representações das narrativas de professores e professoras configuram nas relações de trabalho como negatividade a individualização, pondo o trabalho docente como um trabalho altamente competitivo, que reflete nos aspectos normativos relativos à inserção, acesso, promoção, qualificações e produção científica. É consenso entre os entrevistados que essa realidade reflete as relações de trabalho entre homens e mulheres, na medida em que as relações interpessoais e os conflitos, as dificuldades em lidar com as diferenças marcam a vontade dos/ as docentes, a mudança de um espaço competitivo e individualizado para um espaço de colaboração, cooperação e diálogo; ao menos nos discursos percebe-se essa iniciativa.

No que diz respeito às características e habilidades indispensáveis para as expectativas pessoais e profissionais do desenvolvimento do trabalho docente, os depoimentos dos/as docentes revelam similaridades, sendo possível agrupá-las como: paciência, pontualidade, assiduidade, responsabilidade, gostar do que faz, disponibilidade, comunicação e estar aberto/a à mudança. Tais características e habilidadesrelacionam-se com o fazer docente, as aulas elaboradas, os conteúdos, os planejamentos, as metodologias de trabalho que os/as docentes desenvolvem nas práticas escolares. Quanto à questão se as habilidades e competências para a docência podem ser diferentes, de acordo com o sexo do trabalhador, várias narrativas surgiram, algumas contraditórias e ambíguas. Entre as mulheres, essas diferenças existem e são evidentes nas relações de trabalho, principalmente no tratamento com os alunos e colegas, entre algumas professoras entrevistadas com muitos anos de experiências; já as professoras com menor tempo de atuação dizem já serem superadas essas questões. Entretanto, os homens entrevistados não percebem diferenças entre os homens e mulheres no trabalho desenvolvido, que ambos teriam as mesmas habilidades para o desenvolvimento do trabalho docente:

O sexo não influencia o trabalho a ser desenvolvido, tudo vai depender do grau de comprometimento de cada profissional (Professor, casado, 28 anos, um fitho, Especialista, quatro anos na Rede Estadual).

A meu ver não há essa necessidade, um fator que influencia é a questão social, muitos pais não querem que seus filhos até o fundamental I estudem com docente do sexo masculino (Professor, casado, 50 anos, dois filhos, Especialista, 18 anos na Rede Estadual).

Já trabalhei em algumas cidades do Estado e a minha experiência me diz que as habilidades e competências na docência não estão no sexo do trabalhador, mas sim, no compromisso profissional com a docência (Professor, solteiro, 40 anos, Mestrando, oito anos na Rede Estadual).

As narrativas masculinas negam, por vezes, as diferenças referentes às representações sociais de gênero no campo de atuação docente, e dão a ideia de que essas distinções poderiam estar no âmbito social, nas atribuições de papéis masculinos e femininos, nos quais as características das qualificações "tácitas" e informais são definidas como ou mais próximas da imagem ou estereótipo feminino. Esse modelo decorre de uma postura dominante que influencia os processos de socialização, a construção de identidade de gênero, as imagens de gênero, as representações da masculinidade e feminilidade, na medida em que, conforme ensina Cruz:

[...] um macho se construa como identidade masculina, internalizando e incorporando a sua personalidade os valores e normas de comportamento próprios de um homem, e que uma fêmea se construa com identidade feminina internalizando e incorporando a sua personalidade aos valores e normas de comportamento próprios de uma mulher (CRUZ, 2012, p. 20).

A argumentação da autora é muito oportuna para esta Tese, pois, ao destacar as possíveis diferenças entre homens e mulheres no campo do trabalho docente ou como elas se configuram, é possível verificar 
nos argumentos dos entrevistados que as imagens de gênero permanecem associadas ao masculino/feminino, representando estereótipos nas relações entre homens e mulheres. Essa ideia está presente em outros trabalhos acerca das representações de gênero, especificamenteno campo do trabalho, cabe citar algumas considerações de Araújo (2011) sobre as imagens de gênero nas relações de trabalho, visto que, para o autor:

[...] as clivagens entre trabalho de homem e trabalho de mulher são construídos, em função dessa dicotomia entre aquilo que é adequado ao masculino e ao feminino. Isso possibilita a reprodução de territórios de mulheres e territórios de homens nos espaços de trabalho (ARAÚJO, 2011, p. 98).

Nesse sentido, interessa saber se as representações de gênero estão associadas diretamente às habilidades para o trabalho docente, às possíveis formas que são percebidas e confrontadas a partir das identidades de gênero, ou até mesmo, as principais dificuldades enquanto mulher/homem para trabalhar na carreira docente.

Como homem a dificuldade que já aconteceu comigo foi uma perseguição de algumas coordenadoras no ambiente de trabalho (grifamos), devido à religião, pois as pessoas não conseguem separar as relações pessoais das relações de trabalho (Professor, casado, 28 anos, um filho, Especialista, 04 anos na Rede Estadual).

As dificuldades são inúmeras, mas especificando algumas pode-se citar a inserção do homem no curso de licenciatura, isso por que há uma conotação de curso feminino (grifo nosso). No entanto, outras dificuldades são corriqueiras, visto que odia a dia em sala de aula já é um desafio imenso. Dentro do ponto de vista econômico, ideológico político e cultural, várias dificuldades são permanentes. Eis algumas: salário, condições de trabalho, a ligação da docência ao feminino (grifo nosso), etc. (Professor, solteiro, 26 anos, Especialista, três anos na Rede Estadual).

Filhos, sobrevivência, e o principal falta de incentivo financeiro. Um soldado inicial da Polícia Militar ganha mais que um professor formado, sendo difícil manter a minha família (grifo nosso) (Professor, casado, 50 anos, dois filhos, Especialista, 18 anos na Rede Estadual).
A principal dificuldade que vejo não está somente na carreira de docente, mas em todas as outras. Nós mulheres continuamos com a jornada dupla, por mais que haja uma divisão de atribuições domésticas com nosso parceiro em casa (grifo nosso), a maior parcela continua com nós mulheres (Professora, casada, 38 anos, dois filhos, Especialista, 11 anos na Rede Estadual).

Os depoimentos dos/as docentes descrevem as representações sociais de gênero por meio de suas argumentações sobre as possíveis dificuldades na realização/atuação no trabalho docente. Embora se perceba que essas identificações são construídas e confrontadas nas interações das relações de trabalho, os/as docentes trazem para essas relações, suas definições prévias do que é masculino e feminino, o que autoriza a dizer que as representações de gênero são o fruto das percepções e práticas sociais construídas pelas trajetórias de cada agente.

Assim, as formas de ver a docência, o sentido do trabalho desenvolvido, as características peculiares da docência estão socialmente ligadas às representações de gênero. Neste sentido, nos depoimentos dos/a docentes, podem-se perceber as identificações masculinas e femininas quando destacados os seguintes trechos das falas "sendo difícil manter a minha família”, "perseguição de algumas coordenadoras no ambiente de trabalho", “a inserção do homem no curso de licenciatura, isso por que há uma conotação de curso feminino", ou até mesmo "continuamos com a jornada dupla”, ou seja, há existência de elementos da "identidade patriarcal" nas argumentações que fazem referência nas imagens ou papéis masculinos e femininos atribuídos no âmbito da relação público/privado. Conforme o depoimento de uma das entrevistadas:

Não é notória assimetrias entre homens e mulheres
no cotidiano do trabalho docente, estando mais para
uma relação de equidade sobre a relação de trabalho.
Contudo, sempre as mulheres conversam mais com
outras mulheres e os homens conversam mais com
outros homens, ou seja, em termos de proximidade
sempre acaba tendo uma reparação entre ambos (gri-
famos), mas sobre as questões ligadas diretamente ao 
trabalho não. No colégio há comentários sobre cargos e professores/as, na medida em que alguns professores em momentos de discussões de problemas não aceitam as ordens da coordenação, dirigida por mulheres. Outro aspecto sobre isso é o tratamento dos alunos, sempre há comentários de que os homens são mais difíceis de ligar, mais duros, mais sérios, e as mulheres não mais maleáveis, mais acessíveis (grifo nosso) e dispostas ao diálogo (Professora, solteira, 37 anos, Especialista, 13 anos na Rede Estadual).
As mudanças de consciência sobre as relações de gênero são fundamentais para entender as identidades/alteridades dos/as docentes, sendo necessárias novas formas de organização do trabalho a fim de ampliar os espaços de socialização da escola, uma vez que essas relações acabam por indissociar as identidades/subjetividades dos/as docentes, em consonância com a atribuição de sentidos ao trabalho, ao aprender e ao ensinar, que suas identidades profissionais e sociais se constroem.

\section{SENTIDO E O SIGNIFICADO DO TRABALHO NA PERSPECTIVA DOS/AS DOCENTES}

O trabalho docente é cansativo, mas é um cheio de interações sociais. Um lugar para adquirir mais conhecimentos, trocar experiências com outros profissionais e, principalmente, de ascensão social, pois com o trabalho você cresce e é reconhecido socialmente. 0 sentido do trabalho para mim é de ascender enquanto mulher, profissional, melhor qualidade de vida, na medida em que com o trabalho o docente nós conseguimos bens materiais (Professora, solteira, 37 anos, sem filhos, Especialista, 12 anos na Rede Estadual).

Destaca-se o depoimento da docente para iniciar a discussão sobre os sentidos e significados da docência. Inicialmente, acredita-se que os sentidos e significados são atribuídos pelos/as docentes com base em suas vivências no trabalho e fora dele, bem como pela construção dos saberes profissionais. As vivências e os saberes docentes são construídos em um campo plural, diverso e dinâmico, que possui as mais variadas fontes de aquisição (família, escolas, universidades, trabalho), isso tanto para o nível médio quanto para os demais níveis de ensino.

Dessa relação, surgem alguns argumentos/justificativas por parte de determinados teóricos, como a concepção do saberes docentes, por exemplo, Tardif (2000, p. 217) que atribui sentido ao trabalho consoante à construção da relação entre trabalho/docente e docente/saber. A ideia do autor é que o significado atribuído ao trabalho pelos/as docentes pode ser influenciados pelas "dimensões temporais do saber profissional, ou seja, sua inscrição na história de vida do professor e sua construção ao longo de uma carreira". Assim, nas vivências e nas construções das identificações dos/as docentes são, também, construídos seus significados.

Acredita-se que os docentes vivem no cotidiano o reflexo das novas configurações do trabalho, tais como a precarização do trabalho, a desvalorização salarial, a falta de estruturação física das instituições de ensino, as novas exigências/competências para o desenvolvimento do trabalho, indícios estes que já foram tema de vários estudos sobre o trabalho de docência em todos os níveis (PEREIRA; FIDALGO, 2008) e que a pressão pela produtividade, a competição entre os docentes e a busca por titulação são condicionantes na vida cotidiana dos/as docentes (CRUZ, 2012).

Nessa perspectiva, os sentidos e significados da docência estão ligados, particularmente, às vivências da sala de aula, do fazer docente cotidiano. A sala de aula se configura como um espaço de construções de saberes docente e de mediação desses saberes, no qual os/as docentes vivenciam várias experiências de socialização significativas que influenciam suas 
vidas. Observa-se, também, que é nesse espaço da carreira docente que se iniciam suas trajetórias profissionais e suas identificações pessoais de acordo com os significados do trabalho docente para homens e mulheres. Assim, de posse dos depoimentos e argumentações dos/as docentes foi possível concentrar as representações dos sentidos e significados do trabalho em dois grandes aspectos: a positividade e a negatividade da docência. Quanto aos aspectos positivos do trabalho docente, destacam-se os seguintes depoimentos:

É a satisfação que você sente, de contribuir na formação de outras pessoas, isso é central, visto que todo professor ou pelo menos os que eu converso, destacam em grande perspectiva, a satisfação de ter contribuído com a formação de muitos no decorrer de seu trabalho, bem como pelo seu reconhecimento, porque é uma profissão muito bonita, que dá legitimidade ao professor no campo financeiro, haja vista que se fala tanto da profissão docente, mas dentro do mercado de trabalho há outras profissões que são menos valorizadas, ou seja, eu sei que o professor não ganha muito bem, não é uma das piores profissões, pois na docência você tem mais abertura para, além do trabatho fixo, desenvolver atividades extras que contribuem para o aumento da minha renda mensal. 0 que precisa é que o professor entenda esse processo e desenvolva suas atividades com dedicação porque a discussão entre professor/aluno, professor/professor é significativa para a construção do sentido do próprio trabalho. Eu não sou uma docente que só pensa a educação negativamente, pois acredito que ela tem avançado muito, muitas coisas foram legitimadas a partir de lutas de vários pensadores de diferentes épocas através do processo de questionar a educação, sua estrutura e seu desenvolvimento (Professora, solteira, 47 anos, dois filhos, Doutora, 15 anos na Rede Estadual).

A positividade do meu trabalho é sempre ver o sucesso dos meus alunos, quando eles ingressam nas universidades, quando seguem um caminho sério. Hoje, eu tenho alunos que já me medicaram quando estive docente, aluno que desenham casas se solicitarem e isso é o que mais me faz pensar de forma positiva para minha profissão, pois o reconhecimento que não tem preço. É, de fato, o que me motiva a continuar dando aulas e estudando muito sempre (professor, 42 anos, casado, três filhos, Especialista, 13 anos na Rede Estadual).
As argumentações apresentadas por homens e mulheres representam como positividades do trabatho docente o reconhecimento ao trabalho desenvolvido, cuja ótica principal é a subjetividade e identificação dos agentes nesse processo. 0 espaço escolar, na qualidade de espaço de materialização das práticas sociais do professor, reflete-se, por meio de diversas representações, nos depoimentos de professores e professoras sobre os aspectos positivos da docência. Nas práticas escolares, a socialização acontece na rotinização das práticas, nos diálogos, nos conflitos, nas formas com que os/as docentes se identificam, a depender do seu próprio olhar ou do olhar dos outros, refletindo sobre o sentido de pertencimento, de representações que traduzem as imagens positiva de si e dos outros, no trabalho docente.

Parte-se das relações que se estabelecem entre docente/aluno, docente/meio, docente/sociedade para entender os sentidos do aprender e do ensinar dos/as doentes no campo das relações de trabalho. Sob essa perspectiva de análise, Scoz (2011) traz uma discussão semelhante, quando analisou a construção das identidades e subjetividades dos professores, na medida em que entende que por meio dos significados do aprender e do ensinar (REY, 2003), é possível ter acesso à maneira como eles se situam como sujeitos pensantes, bem como às emoções produzidas em diversas situações de ensino e aprendizagem em diferentes momentos e espaços de suas vidas (SCOZ, 2011, p. 49). Assim, quando os/as docentes, em unanimidade, apontam o sentido do reconhecimento, do respeito, da valorização da pessoa, eles descrevem as várias situações, circunstancias e momentos que interferem nas relações de trabalho na docência e que influenciam internamente e externamente suas identificações.

Sobre os aspectos negativos do trabalho docente, os/as professores/as apontaram como mais graves e alarmantes os seguintes aspectos: o baixo investimento na educação; as políticas de cima para baixo; as formas de organização do trabalho e a intensa fornada de trabalho dentro e fora da escola; cobranças 
por mais qualificação; a desvalorização da profissão; a ascensão feminina ao cargo diretivo e as relações de poder de cercam as vivências cotidianas do trabalho docente. Alguns desses argumentos emergem sentimentos de frustrações nas suas vivências:

Nós vivemos em um país capitalista, que, mesmo com pessoas bem intencionadas na educação, alguns aspectos do trabalho docente têm sido prejudicados por um sistema autoritário e de conveniência, haja vista o pouco investimento na educação, as políticas públicas são de cima para baixo, realmente, e que os pacotes de formação docente estão lentamente dando efeito. Outro ponto negativo é que o próprio professor é resistente à formação, a discussão, a comentar sobre suas práticas e experiências (Professora, solteira, 47 anos, dois filhos, Doutora, 15 anos na Rede Estadual).

A questão salarial é muito importante, pois o professor merece muito mais. Eu acredito nisso, sem dúvidas ele merece muito mais. Simplesmente porque o professor é o condutor de todas as profissões do país, inclusive, a de professor que, por sua vez, também passa pelo professor. Acredito que se tivesse um salário melhor poderia ampliar minha capacitação e treinamentos com a participação em cursos de curta duração, na medida em que se sentiria mais estimulado a buscar mais, a investir mais na minha carreira. Fato que não acontece com mais intensidade pelo fato deter que pensar, em primeiro lugar, na minha família e em seu sustento. Contudo, eu atribuo, não só na questão salarial, porque eu acredito que o discurso da educação precisa mudar um pouco, na medida em que não é só a valorização salarial, mas a valorização pessoal em si, que não sedá ao docente da escola pública. Precisamos de mais valorização, mais condições pedagógicas para trabalhar, mais capacitação para a docência, visto que eu acredito na formação continuada, nãodá para desenvolver a educação sem uma formação que dê conta de todas as mudanças atuais (Professor, 42 anos, casado, três filhos, Especialista, 13 anos na Rede Estadual).

As opiniões representam as inquietações e impactos na vida dos/as docentes, a partir das novas configurações das relações de trabalho, e a contribuição da escola nesse processo é o surgimento da mercantilização do ensino. Os papéis dos/as docentes são questionados com base nas questões de relacionamento existente, intricadamente, entre consciente e inconsciente, objetividade e subjetividade, na medida em que essas questões integram o pensamento, as emoções, as situações e vivências dos agentes escolares.

A dinâmica das relações de trabalho e a forma como a escola está organizada hoje priorizam um perfil de profissional conectado com as transformações sociais e com a descentralização do saber contemporâneo, visto que a figura do professor, como concentrador da informação, perde o foco, e entra em cena o facilitador com experiência (CRUZ, 2012, p. 225). Contudo, já se sabe que as relações professor/aluno, professor/saber, professor/escolasão pautadas pela diversidade, e são descentralizadas, pois todos os agentes são participantes ativos, e não mais neutros, no processo educativo.

Os depoimentos dos/as docentes mostram que nas relações cotidianas de trabalho, o sentido do fazer e do ser é diverso e atende as dinâmicas de suas vivências dentro e fora do trabalho. Ao expressarem quanto ao significado do seu trabalho, os/as docentes atribuem sentido ao desempenho do seu fazer e a relação direta que isso exerce sobre a construção dos saberes docentes (teóricos, práticos, organizacionais, profissionais). Entretanto, percebe-se que esse processo é composto por contradições, medo, satisfação, cobranças, pressões e insegurança fruto das relações interpessoais; ao mesmo tempo, já existe uma busca pela estabilização dos direitos, bem como pelo enfraquecimento do autoritarismo para o surgimento de uma postura democrática das relações de poder. Cruz (2012), ao analisar o sentido do trabalho na docência sobre a dimensão de gênero, mostra que a articulação das estratégias de poder reflete-se nos discursos de forma objetiva e subjetiva dos/as docentes, por meio de disputas de posições entre os agentes, objetivando ao aumento do determinado capital simbólico.

$\mathrm{Na}$ perspectiva dos/as docentes, o seu trabalho apresenta características que se incorporam às identificações de cada um, em relação ao sentido do exercício da docência, legitimando as representações dos 
significados do fazer docente, e refletem asformas que eles configuram nas suas práticas. 0 sentido da categoria trabalho para as mulheres e homens na carreira docente perpassa pela noção da construção de suas identificações, dos significados de pertencimento e das relações intensificadas no cotidiano. 0 ser professor ou professora relaciona-se com as concepções individuais e subjetivas de homens e mulheres, marcados pela relação de tempo e espaço, referentes às suas práticas docentes no decorrer de suas trajetórias sociais. Neste sentido, Scoz (2011) argumenta que o sentido e as formas como ele se configura nas relações de trabalho dos/as docentes são intensificada a partir de suas trajetórias sociais. Assim:

A subjetividade e identidade podem ser compreendidas como algo em construção, com base nos sentidos que os sujeitos vão produzindo na condição singular em que encontram inseridos em suas trajetórias de vida e, ao mesmo tempo, em suas diferentes atividades e formas de relação. Assim, são o resultado de complexas sínteses das experiências individuais dos sujeitos em diferentes contextos de expressão (SCOZ, 2011, p. 28-29).

0 argumento da autora sobre o sentido do trabalho docente propõe uma análise maior quanto à relação entre subjetividade/identidade dos trabalhadores e as formas com que essa relação é alterada/modificada conforme suas trajetórias. Entende-se que no interior dessas relações, os agentes vivenciam experiências múltiplas dentro e fora do trabalho, pondo à prova a relação entre particularidade/coletividade na compreensão dos sentidos atribuídos pelos/as docentes. Assim, a partir da análise dos depoimentos acerca dos significados do trabalho docente, é possível perceber que se constituem privilégios dos/as docentes a compreensão do sentido da profissão e as formas com que esta foi sendo produzida, por meio da construção dos saberes do "aprender" e "ensinar" em suas trajetórias de socialização.

\section{TRABALHO COMO UMA CATEGORIA CENTRAL E IMATERIAL NA VIDA DOS/AS DOCENTES}

A imaterialidade e a centralidade são categorias analíticas ambíguas nos debates teóricos das ciências humanas. No caso específico desta pesquisa, ambas foram bastante citadas e refletidas nos argumentos e discursos dos/as docentes sobre as vivências na docência na contemporaneidade. Tais inquietações revelam dois grandes aspectos da docência: por um lado a centralidade do trabalho na vida dos professores se intensifica em suas decisões, vivências, escolhas, permanências nas relações construídas dentro e fora trabalho; por outro lado, a relação entre trabalho/trabalhador e docente/escola tem posto a prova as identificações dos docentes por meio das incertezas do produto do "trabalho docente", haja vista que as subjetividades dos alunos é que são trabalhadas no cotidiano das práticas escolares. Neste contexto, algumas argumentações dos entrevistados sinalizam essa conjuntura:

\begin{abstract}
Ser docente, hoje, é um desafio muito grande, pois educar para uma sociedade que não tem uma boa formação social, uma boa estrutura política tem se tornando um desafio constante, uma vez que acarreta diversos problemas que se manifestam em sala de aula, dificultando, assim, o processo de ensino. Por outro lado, esses problemas podem ser trabalhados no dia a dia, em sala de aula, fazendo, dessa forma, o aluno perceber que é sujeito da sociedade e não apenas um objeto a ser estudado (Professora, solteira, 46 anos, dois filhos, doutora, 15 anos na Rede Estadual).
\end{abstract}

As experiências, as representações e as subjetividades dos/as docentes expostas nos depoimentos apontam para a ideia de centralidade do trabalho na vida dos/as docentes, embora convivam com a imaterialidade do produto do trabalho desenvolvido. Antes de adentrar mais nas justificativas e falas dos/as docentes sobre a centralidade e imaterialidade do traba- 
Iho docente, cabe analisar, rapidamente, alguns argumentos teóricos acerca dessas categorias de análise, em especial, da centralidade ou não do trabalho.

Alguns autores questionam a categoria "trabalho", e propõem a tese sobre o fim da centralidade do trabalho na vida dos trabalhadores ${ }^{3}$. ClausOffe (1989a), por exemplo, ao questionar a categoria "trabalho"nas ciências sociais levanta algumas questões sobre sua centralidade. Para o autor, "o crescimento do setor de serviços", o "declínio da ética do trabalho" e a "ampliação do tempo livre do trabalhador" tem posto à prova a centralidade do trabalho numa configuração tanto objetiva quanto subjetiva na vida dos trabalhadores ${ }^{4}$. Em contrapartida, autores como Lukács (1979; 1991) e Antunes (2009) $)^{5}$ justificam que o trabalho se caracteriza como mediador entre homem e natureza. Para Lukács (1979), o trabalho é uma categoria fundadora do "ser social" e todas as demais categorias já têm em sua "essência um caráter social". Assim, o trabalho possibilita a mudança do natural para o social, ou seja, é no trabalho que o indivíduo encontra o eixo central da "esfera social"6. Antunes (2009), sobre "os sentidos do trabalho", destaca que são dimensões que apontam para a "vigência da centralidade do trabalho" na sociedade contemporânea. Segundo ele, a complexidade das relações de trabalho, tais como entre o trabalho produtivo e improdutivo, manual e

3 Destaquem-se Offe (1985; 1989; 1991), Habermas (1987) e Kurz (1993). 4 Segundo Offe (1989a, p. 177), "a diferenciação interna e contínua da coletividade dos trabalhadores assalariados, assim como a erosão dos alicerces culturais e políticos de uma identidade coletiva centrada no trabalho, ampliaram esses dilemas das formas de trabalho assalariado ou da dependência com relação ao salário não serem mais o foco de intenção coletiva e de divisão social e política. No que diz respeito aos conteúdos objetivos e subjetivos da experiência, muitas atividades assalariadas nada mais têm em comum a não ser o nome trabalho".

5 Organista (2006, p. 130) também contribui com o debate, pois para ele a "centralidade cotidiana do trabalho, bem como a centralidade política dos trabalhadores, é construída e, ao mesmo tempo, é constituinte de valores sócias que tem no ser homem sua origem fundamentada no e pelo trabalho".

6 "Somente o trabalho tem em sua natureza ontológica um caráter intermediário. Ele é essencialmente uma inter-relação entre homem (sociedade) e natureza, tanto inorgânica (utensílios, matéria-prima, objetos de trabalho etc.), como orgânica, inter-relação [...] que se caracteriza acima de tudo pela passagem do homem que trabalha, partindo do ser puramente biológico ao ser social” (LUKÁCS, 1979, p. 14). intelectual, material e imaterial, bem como as novas configurações e identificações dos trabalhadores estão a reafirmar a centralidade do trabalho na contemporaneidade.

Apesar de haver duas linhas de pensamento relativas à centralidade do trabalho, nesta pesquisa adota-se a segunda, a de que o trabalho é uma categoria central na vida dos/as docentes. Esta tomada de posição decorreu da análise dos depoimentos dos/as docentes, haja vista que as novas demandas das relações de trabalho e as complexidades das relações objetivas e subjetivas, produtivas e não produtivas, intelectual e imaterial da docência põem em evidência a importância e a contribuição do trabalho nas vidas dos/as docentes. Os argumentos que seguem sinalizam essa realidade:

Meu trabalho é central para mim porque toma uma grande parte do meu tempo, vivo em função das minhas aulas, me capacito o tempo todo para que minha prática seja significativa, por esses motivos ele é central na minha vida. 0 trabalho é central porque eu não me vejo em outro segmento profissional, pela questão da idade e pela questão de tudo que eu já alcancei, visto que conseguichegar onde queria e também me identifico com o processo de formação, o processo de formar e capacitar, trabalhando com capacitação docente em consultorias no decorrer na minha vida profissional. Eu acredito que o docente precisa descobrir a área ou nível de ensino que se identifique, pois só assim, o docente fará um trabalho diferenciado e central, visto que o docente pode realizar-se com o desenvolvimento de atividades técnicas, nas intervenções pedagógicas, tudo isso é um fazer, na qual o docente pode também fazer um trabalho de dedicação (Professora, solteira, 47 anos, dois filhos, Doutora, 15 anos na Rede Estadual).

Totalmente central, porque trabalho muito, passo muito tempo planejando minhas aulas a ponto de passar mais tempo com o trabalho do que com a família ou o lazer (Professora, casada, 49 anos, três filhos, Especialista, 17 anos na Rede Estadual).

É o que eu faço, é do que eu vivo, do que gosto de fazer e do que eu faço de melhor. Na verdade, eu gosto de fazer e executar esse trabalho, pois no processo me sinto bem quando estou trabalhando. Com isso, penso que tenho colhido bons frutos, tanto é que muitos 
alunos, se não a maioria, gostam do meu trabalho e indicam sempre meu nome para as palestras e cursos (Professor, casado, 39 anos, um filho, Mestre, 15 anos na Rede Estadual).

Parte-se do princípio de que o trabalho é uma categoria central na vida dos trabalhadores, haja vista que os depoimentos demonstram como o mesmo se configura, como um eixo central na vida dos/as docentes. Eles/as compreendem o trabalho, as relações no trabalho, a sociabilidade no trabalho como aspectos relevantes para o processo de construção social, haja vista a dedicação para o desenvolvimento das atividades do trabalho. Há uma forte relação entre trabalho a valorização da sociabilidade dos docentes no agir cotidiano das práticas laborais, a qual constrói um espaço de valorizações das subjetividades dos trabalhadores, fundada nas práticas sociais em que os/as docentes se inserem dentro e fora do trabalho.

A importância do desempenho do trabalho para a vida dos/as docentes está ligada às formas/alternativas que ambos criam no decorrer da atuação na esfera familiar e na do trabalho. Percebe-se que nesse processo as identificações masculinas e femininas são testadas nos diferentes espaços de socialização por meio das conexões existentes entre a realização do trabalho e as práticas interativas, as subjetividades e coletividades dos trabalhadores como elementos que constroem as práticas sociais.

Segundo Antunes (2009, p. 136), a sociabilidade encontra-se no próprio ato de trabalhar, pois o trabatho se configura como uma categoria intermediaria o salto ontológico das formas pré-humanas para ser social. Ele está no centro do processo de humanização do homem. No caso da docência, esta se centra nas possibilidades de ascensões dos/as docentes, nas novas formas de articulação das esferas pública e privada, nas novas configurações de organizações e relações de trabalho nas instituições, nos sentidos e significados que homens e mulheres atribuem ao processo de qualificação para o trabalho e nas rupturas e continuidades dessas relações. A centralidade do trabalho perpassa pela ampliação dos saberes docente (teóricos, práticos, profissionais) e estruturam/desestruturam as identificações dos/as docentes a partir das relações internas e externas. 0 resultado do trabalho e o desenvolvimento dos pilares "ter", "fazer", "ser" e "saber" da docência é imaterial.

A perspectiva do trabalho imaterial e subjetividade defendida por Lazzarato (2001) é muito significativa para essa discussão, visto que o trabalho docente se caracteriza como uma atividade laboral "abstrata” ligada às subjetividades dos trabalhadores. Para o autor:

Quando o trabalho se transforma em trabalho imaterial e o trabalho imaterial é reconhecido como base fundamental da produção, este processo não investe somente a produção, mas a forma inteira do ciclo "reprodução-consumo": o trabalho imaterial não se reproduz (e não reproduz a sociedade) na forma de exploração, mas na forma de reprodução da subjetividade (LAZZARATO, 2001, p. 30).

O argumento do autor é significativo para a análise do desempenho do trabalho do setor de serviços, no qual a docência se coloca. Nessas funções, o valor do trabalho desenvolvido centra-se nas subjetividades dos/as trabalhadores/as, no plano das identificações e nas formas de desenvolvimento do trabalho. Foi possível perceber nos depoimentos dos entrevistados a dificuldade de lidar e aceitar o produto final do seu labor na docência, na medida em que os/as docentes trabalham nas práticas escolares cotidianas as subjetividades dos alunos:

No processo de trabalho, a gente já percebe que você contribuiu com a aprendizagem significativa do aluno, pois, no decorrer do processo, você olha e vê os alunos aprendendo, quando eles reconhecem que eu fiz parte da vida dele, que aprenderam através da minha mediação, ou seja, essa é uma contribuição que você já vem percebendo no decorrer de sua prática e isso lhe dá força e ênfase para continuar. Embora não se perceba o produto final da docência fato que frustra muito, no processo fica notória nossa contribuição (Docente, casada, 49 anos, três filhos, Especialista, 17 anos na Rede Estadual). 
Olhe, é complicado, pois hoje é difícil você vê o resultado, saber ou medir as subjetividades dos alunos, digamos que não sei se existe aprendizagem zero ou de $100 \%$, bem como o acompanhamento de vários alunos com desenvolvimentos diferenciados. Isso me frustra muito, não só a mim como a todos os professores, pois eu não conheço um professor de inicio ou fim de carreira que não esteja frustrado com o resultado do seu trabalho. É frustrante porque para a sociedade não está tão visível o resultado do meu trabalho (Docente, casada, 29 anos, sem filhos, Especialista, 04 anos na Rede Estadual).

Embora seja de fato imaterial nosso resultado, as conquistas dos nossos alunos dia a dia são o retorno ou o principal resultado do desenvolvimento do nosso tra- balho, às vezes me frustra, mas continuo forte e firme
no empenho de transformar ou ampliar essas conquis-
tas (Docente, solteiro, 40 anos, sem filhos, Mestrando, 08 anos na Rede Estadual).

Os argumentos dos/as docentes sinalizam a importância do trabalho para o desenvolvimento social, para a socialização e as inter-relações dentro e fora do trabalho. Entretanto, a falta da visibilização do produto final do seu trabalho propõe aos docentes um estado de "zona de fronteira" entre o material e imaterial, objetivo e subjetivo, individualidade e coletividade, que limitam ao cotidiano das práticas escolares as formas de percepção e legitimação de seu trabalho.

\section{CONSIDERACÕ̃ES FINAIS}

Neste trabalho, além de responder as questões preestabelecidas para investigação inicial, procurou-se levantar no processo outras indagações relativas às relações de gênero no trabalho docente do Colégio Estadual Atheneu Sergipense, na medida em que as problemáticas referentes às representações sociais de gênero no campo da educação, no trabalho docente, sobre as qualificações e as mudanças nas relações do mercado de trabalhos e configuram como um campo multidisciplinar de análise. Infere-se que as discussões acerca das relações de gênero no trabalho avançam em alguns setores e em outros ainda permanecem como tema com menos significância sob diferentes perspectivas interpessoais dos investigadores, justificando o interesse inicial desta pesquisa sobre as diversas dinâmicas que o trabalho docente tem perpassado numa perspectiva internacional/nacional, macro/micro, ge$\mathrm{ral} /$ particular e objetiva/subjetiva.

Ainda que a preocupação desta pesquisa voltasse para as experiências desenvolvidas entre o feminino e o masculino, a abordagem do objeto desta pesquisa, no plano teórico e prático, centrou-se nas experiên- cias de professores e professoras, entendidos como sujeitos da história e do processo de trabalho. Isso significou tentar compreender, em seu próprio campo de atividade profissional, as representações por meio das quais os docentes trabalhadores procuram explicar a realidade em que se acham inscritos, e elaboram uma fala própria sobre si mesmo, identificando, polemicamente, os significados do feminino e o masculino não só como imagem, mas, sobretudo, como relações que se formam no interior de uma situação específica.

Neste sentido, a hipótese central de que mulheres e homens docentes do ensino médio do Colégio Estadual Atheneu Sergipense atribuem sentidos e significados diferentes ao trabalho e à qualificaçãose confirma. Isto acontece conforme a definição dos lugares atribuídos a homens e mulheres, a trajetória no trabalho e na família, e os aspectos que influenciam na construção de projetos e expectativas pessoais e profissionais, que passam a ser vividas de maneira diferenciada por homens e mulheres. Contudo, se faz necessário continuar estes estudos para ampliar a evolução, teórica e empírica desse processo. 
Compreende-se que nesse processo de escolhas e decisões, o investigador muito se questiona, se influencia e se adapta às mais variadas situações e desafios do campo investigado, principalmente, dos agentes envolvidos. Ao optar pela elaboração de questões iniciais específicas para a pesquisa, destaca-se como elas foram significativas para nortear o desenvolvimento do trabalho, tendo como definição os procedimentos teórico-metodológicos adotados para compreender as relações sociais de gênero construídas no trabalho docente, de forma a ser orientada para os objetivos elaborados e a tese a ser defendida.

Nesse sentido, para as considerações conclusivas deste trabalho destacaram-se as principais respostas das questões norteadoras e objetivos da pesquisa. No que se refere à caracterização do perfil dos/as docentes da Rede Estadual de Ensino de Sergipe e do Colégio Estadual Atheneu Sergipense, esta foi realizada por meio da coleta de dados do Educasenso 2010, do SIGA e da aplicação de questionários aos docentes no decorrer do ano de 2011. Homens e mulheres docentes do Colégio Atheneu Sergipense são trabalhadores/as do magistério estadual de nível médio com um perfil diferenciado (nível de escolarização, níveis de atuação, rendimentos, o sexo, idade, estado civil, filhos, tempo de serviço), em relação a outros profissionais da rede estadual de ensino, com um alto nível de qualificação profissional, nomeados por meio de aprovação em seleção pública. Segundo os dados obtidos, as mulheres representam a maioria dos profissionais da instituição: $59 \%$ em relação aos homens.

Com relação à idade, as mulheres são mais novas que os homens, pois a maioria delas está na faixa etária entre 31 a 35 anos e os homens com mais de 41 anos. Embora a maioria de homens e mulheres sejam casados/as, a pesquisa revela uma tendência no aumento de docentes solteiros/as, ficando muito próximos da faixa etária dos/as casados/as. Quanto à escolarização inicial e atual dos/as docentes foi possível perceber que as mulheres são mais qualificadas em relação aos homens, tanto no processo de inserção quanto durante a atuação como docente. No que se refere ao tempo de serviço na Rede Estadual de Ensino e na Instituição investigada, os homens estão há mais tempo, em ambos com mais de 16 anos, enquanto as mulheres possuem experiência em ambos entre seis e dez anos, bem como entre homens e mulheres se configura a tendência de diminuição do número de filhos.

Ao compreender as novas alternativas de organização do trabalho docente no ensino médio no contexto da globalização, a pesquisa verificou que o trabalho docente obedece a uma formatização estrutural de organização, demarcada intimamente pela relação de tempo/espaço, visto que a Instituição, no decorrer de sua história, passou por várias reformas organizacionais, a fim de se adaptar às exigências educacionais de cada época, por um lado, e, por outro, elaborar novas práticas escolares.

A estrutura física propicia uma interação maior entre os agentes escolares, sendo possível perceber uma subdivisão dos espaços em espaços de "atividades meio" e espaços de "atividades fins", ou seja, espaços específicos para realização de atividades com alunos e outros para realização de atividades de apoio ao processo educativo. 0 contexto desses espaços é visto pelos agentes como um processo coletivo de ações a serem desenvolvidas, mas quando se analisou a distribuição/ocupação por sexo, dos espaços físicos do Colégio Atheneu Sergipense foi possível constatar que os espaços são definidos como espaços de docência, de secretaria, de coordenação pedagógica e de direção, na medida em que o nível hierárquico aumenta, a participação feminina é superior à dos homens, exceto no cargo de direção, o que evidencia a continuação masculina no exercício do poder na Instituição.

Outro aspecto que merece destaque é a rotinização desses espaços, nos quais os/as docentes desenvolvem relações de socialização, pois se observou que na rotina dos/as docentes são estabelecidas interações com os alunos no interior das salas de aulas e 
nos corredores, e as interações entre os docentes e funcionários são demarcadas pela diferença de gênero. Os intervalos escolares evidenciam a separação entre homens e mulheres, em lugares específicos para socialização entre os homens e entre as mulheres, sinalizando as representações das identificações masculinas e femininas, as formas com se percebem dentro das relações de trabalho.

Contudo, no que se refere à participação dos/as docentes na estrutura organizacional curricular da instituição, a pesquisa verificou que há uma ampliação na participação feminina em vários componentes curriculares, principalmente, naqueles considerados de maior atuação masculina como é o caso da área do conhecimento Ciências da Natureza, Matemática e suas Tecnologias. Assim, compreende-se que a escola é um espaço de interações, que organiza o trabalho de homens e mulheres, exercendo influências e causando impactos nas vidas dos trabalhadores.

Ao analisar as condições de trabalho docente a partir das trajetórias profissionais no ensino médio, verificando as possíveis desvantagens entre homens e mulheres na ascensão funcional e nas condições de trabalho, foi possível perceber as especificidades da instituição no trabalho organizacional para a estabilização das condições de trabalho entre homens e mulheres. Contudo, observa-se que, embora a escola organize suas práticas escolares dando condições de trabalho iguais para homens e mulheres, as diferenciações se representam nas formas de inserções/permanências, nas trajetórias percorridas e nos processos de experiências de socialização.

Acerca das formas de inserção e dos motivos para permanência no trabalho docente, verificou-se que as identificações masculinas e femininas se interligam a natureza do trabalho docente, visto que os homens argumentam quanto às necessidades do primeiro trabalho e as mulheres descrevem o campo da educação como o lugar de realização de suas primeiras experiências profissionais. Observou-se que os diferentes tempos vividos pelos professores e professoras nos seus processos de escolha profissional relacionam-se diretamente com suas trajetórias, o que justifica as escolhas masculinas devido à facilidade de ingresso no mercado de trabalho e à falta de oportunidades em outros setores; e escolhas femininas haja vista as influências familiares e a proximidade com os atributos que caracterizam a natureza da mulher para a inserção no mercado de trabalho.

A pesquisa concluiu que o processo de inserção na carreira docente é diferenciado a partir do sexo do trabalhador, na medida em que os homens entram na carreira docente diretamente por concurso público, já as mulheres destacam que passaram por experiências de contratos de professoras para atuarem em escolas públicas ou privadas em séries/etapas de ensino inferiores à que atuam hoje. Sob outro olhar, foi possivel perceber que, embora homens e mulheres tenham as mesmas oportunidades de inserção no trabalho docente da Instituição, as oportunidades de inserção nos cargos de poder de decisão (direção) historicamente são marcadas por uma ocupação desigual entre homens e mulheres.

Observou-se que as trajetórias e a diversidade de experiências de socialização dos/as docentes são relevantes para a análise das relações sociais de gênero no campo do trabalho docente, na medida em que nas trajetórias de vida dos/as docentes se configuram os sentidos e significado do trabalho, privilegiando suas formas de produção/reprodução nos espaços de socialização e na relação entre formação/trabalho/contexto familiar. Nesta linha de reflexão, as trajetórias de escolarização são utilizadas por homens e mulheres como ferramentas de inserções, permanências, estabilização dos direitos e diminuição das exclusões.

Contudo, cabe dizer que o processo de construção de conhecimento de cada professor/a se dá numa formação plural, temporal e espacial com base nos percursos vividos, e apontam as representações das masculinidades e feminilidades a partir da relação entre 
o que se aponta como tradicional e o que se percebe como moderno. Em outras palavras, pode-se dizer que as trajetórias escolares descrevem o percurso formativo de homens e mulheres, numa visão positivo/negativa das identificações, na qual as memórias da escolarização são fruto de suas vivências e representam os discursos masculinos e femininos.

As trajetórias profissionais descrevem o processo do "tornar-se" professor/a num campo demarcado pelas relações sociais e configuram a organização do trabalho docente. Assim, a partir das narrativas, pode-se inferir que os caminhos, vivências e experiências profissionais de homens e mulheres são diferentes até se inserirem no Colégio Atheneu Sergipense, visto que os homens sinalizam que suas experiências profissionais deram início a partir da admissão por concurso público na carreira docente; já as mulheres descrevem suas vivências em várias etapas/séries de ensino antes de adentrarem no quadro docente permanente da Rede Estadual de Ensino de Sergipe, bem como por vivências de relações de contrato de trabatho precarizadas.

Sobre as trajetórias familiares, constatou-se que, embora a articulação entre o público e o privado como espaços de representações de papéis masculinos e femininos ainda estejam ligadas às relações patriarcais, novas perspectivas dessas representações estão surgindo a partir das próprias trajetórias de homens e mulheres, particularmente, com a inserção e atuação feminina no campo da educação. A diversidade de características dos/as docentes mostrou-se relevantes para a configuração dessas trajetórias familiares, na medida em que suas socializações, decisões, rupturas e continuidades influenciam as representações dos sentidos do trabalho e família para homens e mulheres.

Ao conferir a noção de competência e qualificação no discurso de professores e professoras foi possível perceber as representações sobre os processos de qualificação/treinamentos e a compreensão da valorização das qualificações no "saber-fazer" docente.
Como principais resultados, aponta-se que o sentido atribuído ao processo de qualificação para docência se dá de forma contínua, visto que existe um alto nível de competição e produtividade entre os docentes, sendo requisito para a inserção e permanência no Atheneu Sergipense com privilégio social e financeiro de trabalhar em tempo integral.

Em outras palavras, os sentidos que homens e mutheres atribuem ao processo de qualificação refletem como suas identificações/subjetividades são testadas em diversas situações no interior/exterior das relações de trabalho. Ao averiguar a existência de diferenças/ desvantagens entre homens e mulheres no processo de qualificação, tanto o discurso da direção da Instituição quanto dos/as docentes sinalizam que não há diferenciações de gênero no processo de qualificação. Entretanto, o processo de qualificação está refletindo nas novas habilidades e competências exigidas para as práticas escolares, independente do sexo do trabalhador, mas as representações das masculinidades e feminilidades no interior das relações de trabalho parecem conter uma valorização diferente das qualificações, emergindo a ideia de habilidades ligadas às esferas "públicas e privadas”, em especial, as “qualificações sociais femininas”.

Os/as docentes integram/harmonizam o desempenho profissional e doméstico a partir do diálogo, criando estratégias para conciliar o trabalho docente com as responsabilidades familiares, negociando com esposo/a para minimizar as principais consequências do trabalho sobre sua vida familiar. As mudanças na qualidade do trabalho familiar e as novas formas de organização do espaço doméstico estão sendo repensados para a ampliação da equidade ou estabilização dos papéis sociais de gênero, visto que a pesquisa mostrou que as mulheres são as que mais chefiam suas famílias, com $77 \%$ das casadas e divorciadas como salário principal e como chefes de família. 0 resultado dessas mudanças é a hipótese de que o orçamento familiar é mantido por dois provedores, dupla jornada feminina, externalização do trabalho doméstico e uma inversão de papéis nas relações tradicio- 
nais de gênero, ou seja, mais mulheres exercendo trabalho remunerado e mais homens realizando trabalho não remunerado. Mais que isso, a dimensão da alteridade contribui para a ampliação da cidadania e dos direitos das mulheres e homens nesta relação, na medida em que as relações familiares se configuram como um espaço de negociação entre si e do outros.

Diante das reflexões e discussões abordadas em um tema tão dinâmico e complexo, é impossível ter a pretensão de ter estudado e compreendido todas as perspectivas da temática. Entretanto, ousou-se refletir acerca das representações de gênero dos/as docentes sobre os sentidos e significados atribuídos ao trabalho, à qualificação e às relações familiares, com o objetivo, não apenas de atender aos critérios do doutoramento, mas, principalmente, discutir acerca das relações estabelecidas entre homens e mulheres na docência, campo de atuação profissional do pesquisador.

\section{REFERÊNCIAS}

ARAÚJO, Flávio G. B. da Silva. As relações de gênero no trabalho: um estudo de caso do Hipermercado Super Varejo, São Cristóvão, 2011. (Dissertação de Mestrado em Ciências Sociais do Programa de Pós-Graduação em Ciências Sociais, Universidade Federal de Sergipe).

BRUSCHINI, Cristina. Trabalho e gênero no Brasil até 2005: uma comparação regional. In: BRUSCHINI, Cristina et al. Mercado de trabalho e gênero: comparações internacionais. Rio de Janeiro: FCV, 2008.

CRUZ, Maria Helena Santana. Trabalho, Gênero, Cidadania: Tradição e Modernidade. São Cristóvão: UFS, 2005.

CRUZ, Maria Helena Santana. Refletindo sobre a diversidade de gênero no campo da Educação. In: Revista Saberes em Perspectivas, v. 2, n. 2, jan/abr, 2012, p. 13-32.

CODO, Wanderley. Educação: carinho e trabalho. 4. ed. Petrópolis-RJ: Vozes / Brasília: Confederação Nacional de Trabalhadores em Educação: Universidade de Brasília. Laboratório de Psicologia do Trabalho, 2006.
DIAS, Alfrancio Ferreira. Dos Estudos Culturais ao Novo Conceito de Identidade. Revista Fórum Identidades, GEPIADE, Ano 5, v. 9, jan-jun 2011, p. 152-166.

DUBAR, Claude. A socialização: construção das identidades sociais e profissionais. São Paulo: Martins Fontes, 2005.

GEORGES, Isabel. Entre vida doméstica e vida profissional: engenheiras no Brasil e na França. In: BRUSCHINI, Cristina et al. Mercado de trabalho e gênero: comparações internacionais. Rio de Janeiro: FCV, 2008.

HIRATA, Helena; KERGOAT, Danièle. La divisiondutravailrevisitée. In: MARUANI, M. Lesnouvelles fronteires de l'inégalité, hommesetfemmessurlemarchédutravail. Paris: La Découverte, 1998.

PEREIRA, J. S. F. FIDALGO, F. Quem é essa profissão? Trabalho docente no ensino superior privado e relações sociais de sexo. Disponível em: <http://www. senept.cefetmg.br/galerias/arquivossenept/anais/ tercatema3/terxatema3poster1.pdf>. Acesso em: 28 jun. 2012. 
RIZAVI, Sayyid Salman; SOFER, Catherine.Trabalho doméstico e organização do tempo dos casais: uma comparação internacional. In: COSTA, Albertina de Oliveira; SORJ, Bila;

BRUSCHINI, Cristina; HIRATA, Helena. Mercado de Trabalho e Gênero: comparações internacionais. Rio de Janeiro: FCV, 2008.

SCOTT, Joan. Gênero: uma categoria útil de análise histórica. Educação e Realidade, v. 20, n. 2, jul/dez, 1995, p. 71-99.
SCOZ, Beatriz Judith Lima. Identidade e subjetividade de professores: sentidos do aprender e do ensinar. Petrópolis: Vozes, 2011.

TARDIF, M. Saberes profissionais dos professores e conhecimentos universitários: elementos para uma epistemologia da prática profissional dos professores e suas consequências em relação à formação para o magistério. Revista Brasileira de Educação, n. 13, jan-abr. ANPED, Editora Autores Associados: Campinas, 2000, p. 5-24. 